\title{
EVOLUÇÃO HISTÓRICA DA PROTEÇÃO LEGISLATIVA DOS REFUGIADOS NO BRASIL: UMA BREVE ANÁLISE NO PLANO INTERNO E INTERNACIONAL
}

\section{Resumo:}

Edson Oliveira da Silva*

A presente pesquisa tem como objetivo realizar uma análise da evolução legislativa voltada a proteção dos refugiados que ingressam no território brasileiro. Diante desse fato, questiona-se qual o grau de proteção, historicamente, conferida pela legislação brasileira aos pedidos de refúgio? A indicação da resposta ao problema será produzida a partir de pesquisa bibliográfica e documental, assim como, por meio da análise de dados relacionados ao tema proposto. Por fim, pretende-se traçar um panorama geral do instituto de refúgio e sua relação com os direitos humanos.

Palavras-chave: Refugiado; Convenção; Princípios; Proteção; Dignidade; Direitos Humanos.

\section{HISTORICAL EVOLUTION OF THE LEGISLATIVE PROTECTION OF REFUGEES IN BRAZIL: A BRIEF ANALYSIS ON THE INTERNATIONAL AND INTERNATIONAL PLAN}

\begin{abstract}
:
This research aims to carry out an analysis of the legislative evolution aimed at protecting refugees entering Brazilian territory. Given this fact, the question is what degree of protection has historically been given by Brazilian legislation to refugee requests? The indication of the answer to the problem will be produced from bibliographical and documental research, as well as, through the analysis of data related to the proposed theme. Finally, it is intended to draw an overview of the refugee institute and its relationship with human rights.
\end{abstract}

Keywords: Refugee; Convention; Principles; Protection; Dignity; Human Rights.

\section{INTRODUÇÃO}

$\mathrm{Na}$ sociedade atual, um dos principais debates, sem dúvida, se refere à proteção conferida aos refugiados, uma vez que o número de conflitos armados em vários países cresce exponencialmente. Além disso, o pedido refúgio pode ocorrer em decorrência de atos discriminatórios das mais diversas naturezas, principalmente em países localizados na região

\footnotetext{
* Bacharel em Direito. Pós-graduado em Direito Penal e Processo Penal. Doutorando em Direito pela Universidad de Buenos Aires. Mestre e Doutorando em Desenvolvimento e Meio Ambiente pela Universidade Federal de Sergipe. Professor de Direitos Humanos. Endereço postal: Rua Pureza Bomfim, n ${ }^{\circ}$, Bairro Santos Dumont, Aracaju-SE, CEP 49.087-500. Endereço eletrônico: edsonoliveira@ prof.fanese.edu.br.
} 
do Oriente Médio e, como exemplos mais próximos da realidade brasileira, têm-se os pedidos de refúgio dos venezuelanos.

Os fatores determinantes que geram os movimentos migratórios de refugiados estão, intimamente, relacionados às violações de normas de direitos humanos que suprimem as condições mínimas para uma vida mais digna e justa, principalmente para quem vive em situação de vulnerabilidade social e/ou econômica.

Como foi mencionado, várias são as hipóteses que levam as pessoas a buscarem refúgio fora de seus países, considerando como mais comuns os deslocamentos decorrentes de atos discriminatórios por motivos de nacionalidade, raça, religião, opinião política, pedidos de refúgio por deslocamentos por desastres ambientais ou mesmo por pertencerem a determinado grupo social e em decorrência de conflitos armados.

$\mathrm{Na}$ sociedade atual, o aumento do número de conflitos armados e/ou graves violações dos direitos humanos em todo o mundo tem levado dezenas de milhões de pessoas a deixar seus países, em troca da proteção de suas próprias vidas e de suas famílias. Tais eventos vêm ocorrendo principalmente em países asiáticos de língua árabe, países como Afeganistão, bem como em parte do continente africano e, recentemente, na Venezuela. Diante disso, lançou-se a seguinte problemática: qual o grau de proteção e acolhimento conferido pela legislação brasileira (constitucional e infraconstitucional), oferecidos historicamente aos pedidos de refúgio e no reconhecimento da condição de refugiado aos imigrantes que ingressaram no território brasileiro?

O trabalho aborda um tema de grande relevância, principalmente nos dias atuais, mas ainda pouco discutido, pois é notório o desconhecimento desse tema por boa parte da população. Para tanto, serão analisadas bibliografias nacionais e estrangeiras especializadas no assunto. Assim, o objetivo deste trabalho resume-se na análise da evolução legislativa que delineia os procedimentos a serem adotados pelos órgãos responsáveis pelo reconhecimento do estatuto de refugiado, o grau de eficácia no processamento dos pedidos de refugiado e no reconhecimento do status de refugiado aqueles que ingressam no território brasileiro.

Desta forma, vislumbra-se a grande relevância jurídica que a questão dos refugiados traz para a proteção dos direitos humanos, principalmente, porque os fluxos migratórios são considerados como consequência da violação de direitos humanos fundamentais, que acabam 
por trazer reflexos não apenas no campo do direito, mas indiretamente acabam refletindo seus efeitos na esfera social.

Além disso, o desenvolvimento da pesquisa ocorreu por meio da análise dos elementos históricos que exerceram forte influência nos movimentos migratórios em todo o mundo, refletindo doutrinariamente acerca da diferença de asilo e refúgio. Na pesquisa é apresentado também o avanço linear dos principais diplomas estrangeiros e nacionais que tratam da proteção dos refugiados. O crescimento exponencial do fluxo de migrantes em todo o mundo tem gerado grande preocupação na comunidade internacional, bem como a relevância jurídica que acarreta a violação de direitos básicos destes refugiados também tem sido motivo de preocupação.

Neste artigo, a metodologia aplicada utiliza o método dedutivo, que visa analisar e sintetizar as principais questões que envolvem os refugiados, recorrendo à pesquisa documental e bibliográfica e, à aplicação da análise de conteúdo as informações coletadas.

O estudo incidirá, inicialmente, sobre o surgimento e evolução histórica dos fluxos migratórios em todo o mundo, de modo a apresentar o surgimento e evolução dos principais atos jurídicos e organismos internacionais responsáveis pelo acolhimento de refugiados. Como citado, na continuidade deste estudo será diferenciado os institutos do asilo do refúgio, assim como, será analisada a Convenção de 1951, documento que é considerado um dos principais pilares do desenvolvimento do Direito Internacional dos Refugiados e da proteção conferida a essas pessoas.

Por fim, será abordado o Protocolo de 1967, que ampliou o conceito de refugiado previsto na Convenção de 1951, removendo as limitações temporais e geográficas contidas na referida convenção. De modo que será traçado um panorama geral do instituto de refugiados no Brasil e seus diplomas legais, em especial a Lei $n^{\circ}$ 9.474/1997, que trata da estrutura dos órgãos que atuam em território brasileiro no tratamento dos refugiados.

Para iniciar a apresentação das informações obtidas com a pesquisa, inicialmente, será realizada uma breve exibição da evolução histórica que alicerçou o aporte legislativo que se tem atualmente de proteção e acolhimento dos refugiados, tanto no plano interno quanto no plano internacional. Em seguida é apresentada a diferenciação entre asilo e refúgio, sendo abordada a caracterização do instituto do refúgio e do Comitê Nacional para os Refugiados (CONARE). 


\section{EVOLUÇÃO HISTÓRICA DA LEGISLAÇÃO DE PROTEÇÃO AOS REFUGIADOS}

Pode-se dizer que a questão da proteção dos direitos humanos remonta a meados do século $\mathrm{XX}$, onde alguns direitos considerados essenciais estavam previstos em diplomas internacionais fragmentados, elaborados no âmbito da Liga das Nações, aproximadamente na década de 1920 (RAMOS, 2014; LIMA et al., 2017).

$\mathrm{O}$ crescimento acentuado dos fluxos migratórios de refugiados acabou por pôr à prova a capacidade dos Estados de acolhimento, expondo as fragilidades e dificuldades ainda enfrentadas por toda a sociedade internacional e organismos encarregados de atuar no domínio da proteção dos refugiados (SALLES; GONCALVES, 2016).

Este campo de proteção envolve sistemas globais e regionais que não são incompatíveis, mas complementares. Inspirado nas disposições e princípios da Declaração Universal dos Direitos Humanos de 1948, constitui um complexo instrumento de proteção dos direitos da pessoa humana em nível internacional (PIOVESAN, 2017).

No que diz respeito aos direitos humanos, Piovesan (2012, p. 295) destaca que, "são universais, inerentes à condição de pessoa e não relacionados às peculiaridades sociais e culturais de uma determinada sociedade, abrangendo não só os direitos civis e políticos, mas também os direitos sociais, econômicos e culturais". Como ressaltado pela autora, os direitos humanos tem como uma das suas principais características a universalidade, de modo, que se direciona a todos os seres humanos de modo indistinto.

Para garantir a efetividade dos direitos humanos e para fortalecer os Estados mais afetados pela guerra, bem como para prevenir o surgimento de outras catástrofes de guerra, a Organização das Nações Unidas (ONU) foi criada em 1945, por meio da Conferência de São Francisco, com a participação de 50 países (PORTELA, 2015).

Visando proteger das graves violações de direitos humanos ocorridas durante a Segunda Guerra, bem como oferecer as bases para a resiliência dos países que foram direta ou indiretamente afetados pelos desastrosos efeitos causados pelos conflitos armados, a Declaração Universal dos Direitos (DUDH) surge como um documento geral que traça parâmetros a serem seguidos voltados para garantir o mínimo existencial de cada indivíduo. 
No que diz respeito aos direitos humanos dos refugiados, Piovesan (2012), defende que o grau de discricionariedade conferido aos Estados quanto ao acolhimento ou não dos refugiados deve ser reduzido, uma vez que se traduz o gozo efetivo do direito à obtenção de refúgio como forma de proteção dos direitos humanos.

Vale ressaltar que, muitos Estados se valem do argumento de que cabe a eles determinar quem pode ou não entrar e/ou permanecer em seu território, uma vez que o controle de suas fronteiras territoriais refere-se ao exercício de sua soberania, de modo que com essa justificativa deixar de acolher os refugiados.

Dentro dessa perspectiva, faz-se necessário diferenciar de forma breve, o asilo do refúgio para que se possa compreender a caracterização social e jurídica de cada um desses institutos.

\section{DIFERENÇA DE ASILO E REFÚGIO}

No que se refere as diferenças entre asilo e refúgio, observa-se que o refúgio é um instituto jurídico no âmbito internacional que tem seu alcance universal. Já o asilo é um instituto jurídico regional, com atuação mais latente na América Latina. O refúgio, como já foi dito, é uma medida de natureza particularmente humanitária, enquanto o asilo é uma medida fundamentalmente política (PIOVESAN, 2012).

Segundo Portela (2017, p. 360) "Refúgio é o ato pelo qual o Estado concede proteção ao indivíduo que se encontre em risco noutro país por motivo de guerra ou perseguição de raça, religião, nacionalidade ou relevância para grupo social”. A definição citada traz uma boa caracterização para o instituto estudado.

Quanto à concessão do status de refugiado ao requerente, na opinião de Rusek (2017, p. 15) depende da caracterização "[...] de perseguição por motivos de raça, religião ou nacionalidade, ou pertencimento a determinado grupo social, ou por opinião política diversa, está fora do país de origem e está impedida de recorrer a ele para salvaguardar os seus direitos". A colocação do autor corrobora com o que já foi apresentado.

Embora existam distinções quanto aos fatores que levam ao reconhecimento entre um ou outro instituto, é certo que ambos (asilo e refúgio) convergem para o mesmo fim, o que segundo Piovesan (2012, p. 317) “[...] é a proteção da pessoa humana”. Nesse sentido, Jubilut (2007, p. 36) destaca que “[...] os institutos têm caráter complementar já que [...] o instituto 
asilar é mais amplo, podendo ser utilizado quando não houver possibilidade de aplicação do instituto mais específico que é o refúgio".

Com a entrada em vigor da DUDH, foi estabelecido um parâmetro para o surgimento de outros diplomas regionais que vieram disciplinar a concessão de asilo e refúgio, como a Convenção Americana de Direitos Humanos de 1969, assinada em San José, Costa Rica, em 22 de novembro de 1969, que acabou seguindo os passos da DUDH (JUBILUT, 2007; PIOVESAN, 2012).

Além dos diplomas legais mencionados, foi promulgada a Convenção sobre Asilo Territorial, assinada em Caracas, Venezuela, em 28 de março de 1954, com a assinatura de 20 dos 35 Estados membros da Organização dos Estados Americanos (OEA). Com relação à mencionada Convenção, observa-se em seu artigo I que tanto a concessão de asilo territorial como o diplomático, constituem atos discricionários do Estado concedente, dada sua posição de soberania perante a comunidade internacional. Consequentemente, nenhum outro Estado pode tentar intervir ou mesmo reprimir o Estado que vem conceder asilo a quem dele necessitar (MAZZUOLI, 2015).

Como já foi dito, o ato de conceder asilo depende da discricionariedade do Estado concedente, que avaliará as peculiaridades de cada caso, a fim de esclarecer se as condições do solicitante podem ser consideradas como uma situação de emergência, especialmente quando oferece perigo potencial à vida ou integridade física, bem como ao direito à liberdade do indivíduo.

O instituto de asilo político no ordenamento jurídico brasileiro é amparado pela Constituição Federal de 1988, sendo também regulamentado em alguns diplomas legais dispersos, como o Decreto no 42.628/1957 (Convenção sobre Asilo Diplomático) e também pela Lei $n^{\circ}$ 13.445/2017 (Lei das Migrações) e outras regulamentações.

No que se refere ao instituto do refúgio com tem sua concessão mais relacionada a proteção dos direitos humanos, ou seja, referindo-se a um direito humanitário, de modo que para facilitar a compreensão de sua abrangência a seguir será exposta sua caracterização.

\title{
4. CARACTERIZAÇÃO DO INSTITUTO DO REFÚGIO
}

\author{
Revista de Direitos Humanos em Perspectiva | e-ISSN: 2526-0197 | Encontro Virtual | \\ v. 7 | n. 2 | p. 126 - 143 | Jul/Dez. 2021.


Antes de promover a caracterização do instituto do refúgio, é importante destacar que o problema dos refugiados apresenta uma construção histórica que começou a ganhar novos contornos com o fim da Primeira Guerra Mundial (1914-1918). No entanto, foi apenas no pós Segunda Guerra Mundial que ela se apresentou como um assunto de interesse global (JUBILUT et al., 2017).

Vale esclarecer que a concessão do status de refugiado, que idealisticamente deveria ser a regra para amparar aqueles que estão em situação de vulnerabilidade, na verdade tem sido exceção. Pois, nem sempre se concretiza o refúgio, são muitos os refugiados que acabam ficando por muitos anos no país de acolhimento sem obter a estabilidade de suas vidas causando sérios prejuízos ao seu núcleo familiar (MOREIRA, 2014).

Com o fim da Primeira Guerra Mundial (1914-1918) surgiu a necessidade de impor limites à soberania dos Estados em questões de interesse internacional. Nesse sentido, como antecessora das Nações Unidas, surgiu a Liga das Nações, cujo principal objetivo era promover questões relacionadas à cooperação, paz e segurança no âmbito internacional, buscando assim maior equilíbrio e proteção (MAZZUOLI, 2015).

Quanto a garantir o apoio às vítimas de guerra que se apresentavam em condição de refugiadas, foi necessário elaborar um documento que, orientasse acerca do que defende o princípio do universalismo dos direitos humanos e que garantisse uma maior proteção ao termo refugiado, previsto na DUDH de 1948, deixando de considerar os conceitos adotados por documentos anteriores que se restringiam a tratar dos fatores étnico-geográficos (JUBILUT et al., 2017).

$\mathrm{Na}$ elaboração do texto referente à Convenção sobre o Estatuto dos Refugiados (Convenção de 1951), os países participantes adotaram uma postura mais passiva, principalmente aqueles que detinham maior poder político e econômico, em relação à definição do termo refugiado, adotando portanto, um conceito que continha elementos limitadores de ordem temporal e geográfica, evitando assim o acolhimento de possíveis imigrantes "indesejados".

Como a Convenção de 1951 ampliou o conceito do termo refugiado, unificando elementos de outros diplomas legais que a precederam, bem como a experiência acumulada ao longo dos anos, o texto final de 1951 ainda apresentava limitações em seu contexto, que 
acabou se tornando uma das mais importantes convenções da história para proteção humanitária (JUBILUT et al., 2017).

Observa-se que os padrões internacionais, embora positivos nos documentos ratificados pelos Estados e incorporados aos ordenamentos jurídicos nacionais, exigem o desenvolvimento de políticas públicas eficazes para alcançá-los, que contam com a participação de instituições internacionais responsáveis pelo atendimento aos refugiados (SALLES; GONÇALVES, 2016).

Por fim, com relação a caracterização dos refugiados no mundo é importante destacar que a Assembleia Geral das Nações Unidas considerou que a limitação à definição de refugiado contida na Convenção relativa ao Estatuto dos Refugiados ia em sentido contrário ao fim pretendido por este mesmo diploma internacional. Sendo que, em 31 de janeiro de 1967, na cidade de Nova York, o Protocolo Relativo ao Estatuto dos Refugiados, também conhecido como Protocolo de 1967 eliminou os termos que limitavam as hipóteses de incidência da Convenção de 1951. Esse panorama legislativo mundial influenciou a evolução histórica da normatização de proteção e acolhida dos refugiados no Brasil. Para evidenciar a mencionada evolução legislativa a seguir será apresentada a realidade brasileira.

\section{CONTEXTO HISTÓRICO E ATUAL DO REFÚGIO NO BRASIL}

O panorama histórico do instituto de refugiados na esfera brasileira começou a ganhar contornos mais bem definidos a partir da década de 1950, durante o Governo Vargas, quando o Brasil, ao participar dos trabalhos da Conferência de Plenipotenciários, assumiu a posição de signatário do Estatuto de Refugiados e apátridas em 15 de julho de 1952, embora tal convenção só tenha sido incorporada ao nosso sistema jurídico durante a década de 1960. A

Agência da ONU para Refugiados (ACNUR) só obteve reconhecimento oficial e autorização do governo brasileiro para a instalação de escritório, no ano de 1982, agindo, entretanto, com as limitações derivadas do sistema de reservas geográficas estabelecido no quadro de adesão à Convenção de 1951 (BARRETO, 2010; JUBILUT et al., 2017).

Ocorre que, devido à cláusula de limitação geográfica estabelecida pelo Brasil, apenas as pessoas de países europeus foram reconhecidas como refugiadas. Em 1982, o ACNUR 
ajuizou uma ação perante as autoridades brasileiras com a finalidade de suspender a limitação geográfica, ampliando assim as hipóteses de acolhimento de refugiados.

Somente com o advento da Constituição Federal de 1988, a chamada Constituição Cidadã, o Brasil oficializou o maior acolhimento e proteção aos refugiados, bem como a garantia dos direitos humanos. Diante dessa situação, ocorreu a transferência do escritório do ACNUR para a cidade de Brasília, em 1989.

Como consequência desse movimento de redemocratização no país, o Ministério da Justiça publicou a Portaria Interministerial $n^{\circ}$ 394/1991, que contemplou um leque ainda maior de direitos voltados à proteção dos refugiados, assim como procedimentos estabelecidos a serem adotados pelos órgãos responsáveis de realizar o processo de acolhimento e prestar assistência aos requerentes de asilo.

Com o advento da Constituição Federal de 1988, passou a ser adotada maior proteção aos direitos humanos, uma vez que sua eficácia constitui um dos objetivos fundamentais da República Federativa do Brasil, estando inclusive prevista em seu art. $4^{\circ}$, II, sendo o ato constitucional a base fundadora de todos os demais instrumentos jurídicos de proteção dos refugiados.

A Lei no 9.474/1997 contém normas que disciplinam a exclusão de quem busca a condição de refugiado, em caso de descumprimento de suas disposições. Título II, que vai das arts. 7 a 10, além disso, apresenta disposições relativas ao ingresso do solicitante de refúgio estrangeiro no Estado brasileiro, fazendo referência, embora de forma geral, ao pedido de condição de refugiado.

Em relação à expulsão de refugiados que se encontram em território brasileiro, o art. 36 da Lei $n^{\circ}$ 9.474/1997 faz referência ao estrangeiro que represente risco à segurança nacional ou à manutenção da ordem pública. As hipóteses de expulsão de refugiado do território brasileiro atendem ao disposto no art. 32 da Convenção de 1951.

Observa-se que nas hipóteses em que a legislação nacional permite a expulsão do refugiado que venha a oferecer riscos ao Estado brasileiro, sua expulsão não será feita de forma arbitrária, mas apenas nos casos em que sua necessidade se justifique havendo a devida motivação para a expulsão (JUBILUT et al., 2017).

Todo procedimento que envolva o processo de expulsão de refugiado sob proteção brasileira deve respeitar todas garantias constitucionais quanto ao devido processo legal, por 
meio da defesa contraditória e ampla, prevista no inciso LV, do art. $5^{\circ}$ da Carta Magna (BRASIL, 1988). Após todo o procedimento, cabe ao Poder Executivo determinar, por meio de Decreto Presidencial, a expulsão do refugiado que venha a colocar em risco a segurança nacional e a ordem pública (JUBILUT et al., 2017).

Como se viu anteriormente, a legislação nacional, como regra geral, não permite a expulsão de pessoas sob sua proteção como refugiados, exceto nos casos em que haja risco para a segurança nacional e a ordem pública. Porém, em relação a esses dois últimos casos, o art. 37 procura defender a aplicação do princípio da não repulsão, evitando que o refugiado que vem a ser expulso do território nacional regresse ao país que deu origem a sua busca por refúgio.

O art. 38 da Lei n ${ }^{o}$ 9.474/1997 trata da cessação da condição de refugiado, que se caracteriza por ser uma das chamadas cláusulas de cessação. Vale destacar que, o status de refugiado é temporário por natureza e deve durar apenas enquanto houver receio pela vida ou integridade do refugiado Como se pode verificar, a referida complementação ocorre por meio de convenções e tratados internacionais, bem como pela legislação interna do país que concede o refúgio.

\section{COMITE NACIONAL PARA OS REFUGIADOS (CONARE)}

O advento da Lei $n^{\circ}$ 9.474/1997, além de incorporar e ampliar o conceito e o arcabouço dos direitos conferidos aos refugiados no ordenamento jurídico brasileiro, também traz inovação no que diz respeito aos agentes responsáveis pela implementação das diretrizes nacionais. A referida lei, traz no Título III, artigos 11 a 16, disposições gerais que zelam pela instituição e funcionamento do Comitê Nacional para Refugiados (CONARE), órgão que compõe a estrutura do Ministério da Justiça, cuja principal característica é a composição multidisciplinar, composta por organizações governamentais, não governamentais e do ACNUR (LIMA et al., 2017).

Destarte, muitas vezes, os imigrantes que entram no território brasileiro em busca de refúgio são desprovidos de qualquer tipo de controle de entrada e documentos de identificação de estrangeiros, como o passaporte (JUBILUT et al., 2017). Assim, a pessoa física que se encontra em situação de perigo iminente ou concreto e que ingressa no território brasileiro em 
busca de proteção deve, o quanto antes, procurar as autoridades competentes que sejam responsáveis pela condução do trâmite legalmente exigido para a concessão da condição de refugiado.

$\mathrm{Na}$ análise dos elementos objetivos e subjetivos fundamentais para a concessão do refúgio, será elaborado um relatório denominado Laudo de Elegibilidade que, nos termos da Lei ${ }^{\circ}$ 9.474/1997 o processo será encaminhado ao Secretário do CONARE, para inclusão na pauta da próxima reunião. Esse parecer deve conter elementos que possam servir para embasar as decisões dos membros do plenário do CONARE (JUBILUT et al., 2017).

No entanto, cabe ressaltar que os integrantes do órgão colegiado responsável pela análise do pedido não estão vinculados às questões abordadas pelo Laudo de Elegibilidade, podendo, inclusive, levantar novas questões sobre o assunto que serão debatidas pelo colegiado.

\section{DADOS SOBRE O REFUGIO NO MUNDO}

O acentuado aumento do fluxo migratório em todo o mundo tem trazido cada vez mais desafios tanto para os governos quanto para os órgãos responsáveis pelo tratamento desse tipo de problema. Segundo dados de 2017, estimava-se que existiam cerca de 40 milhões de pessoas em todo o mundo na condição de deslocados internos, cerca de 25,4 milhões de refugiados e 3,1 milhões de requerentes de asilo, com um total de 68,5 milhões. Pessoas nas condições de migrantes forçados. Com base nos dados de 2017, cerca de 40 milhões de pessoas em todo o mundo na condição de deslocadas internas esperam ter seus direitos humanos restaurados (ACNUR, 2017).

Sobre o sistema de proteção aos refugiados, Piovesan (2017, p. 259) destacar que “[...] as fragilidades e insuficiências do sistema revelam, sobretudo, as fragilidades e insuficiências da proteção dos direitos humanos no âmbito interno dos Estados”.

Nos últimos anos, os principais países responsáveis pela origem dos fluxos de refugiados, em que se destacam: Síria (6,3 milhões), Afeganistão (2,6 milhões), Sudão do Sul (2,4 milhões), Mianmar (1,2 milhão) e Somália (986,4 mil), pois representam aproximadamente $68 \%$ do número de refugiados sob o mandato da ACNUR (ACNUR, 2017). 
Portanto, observa-se que os países mencionados anteriormente e que mais geraram fluxos de refugiados ao redor do mundo encontram-se nos continentes da Ásia e da África, como é o caso da Síria, Afeganistão, Somália e Sudão do Sul. Nos países árabes, o principal fator da crise migratória são os graves danos causados pela guerra civil travada nas últimas décadas, bem como pela ação de grupos rebeldes, como tem ocorrido neste ano de 2021 no Afeganistão. No que diz respeito ao acolhimento de refugiados, os países que mais se destacaram entre os anos de 2010-2017, foram a República Democrática do Irão, Alemanha, Bangladesh e Etiópia.

Como visto com a pesquisa, muitos países dos continentes da Ásia e da África aumentaram no número de pessoas que fugiram na busca por refúgio, sendo que dois países tiveram redução no número de pessoas que saíram na busca por refúgio entre os anos de 2010 a 2017, como no exemplo da República Democrática do Irã, com redução de 9\%, assim como a Síria, que obteve uma redução exponencial de $98 \%$ no número de refugiados (ACNUR, 2017). Depreende-se que grande parte dos pedidos de refúgio decorrem dos conflitos enfrentados pelos país situados na Ásia e na África.

\section{DADOS SOBRE O REFÚGIO NO BRASIL}

No Brasil, segundo dados fornecidos pelo CONARE (2017), estima-se que até 2017 o país tinha cerca de 86.007 pedidos de reconhecimento da condição de refugiado em andamento. Porém, até aquele ano, o Estado brasileiro havia reconhecido apenas 10.145 refugiados, o que mostra que o número de pedidos que estavam em andamento a época representava cerca de $748 \%$ do número de refugiados efetivamente reconhecidos.

Lima et al. (2017) alerta para o fato de que o reconhecimento da condição de refugiado no Brasil ainda está em patamar inferior ao ideal, se comparado a outros países sulamericanos, dadas as proporções geodemográficas do Estado brasileiro. No Brasil, os dados mostram que em 2018 e no início de 2019 houveram evidências de uma tendência crescente no número de refugiados hospedados, em grande parte devido aos conflitos na Venezuela.

Quanto ao sistema interamericano, deve ser interpretado a partir de sua origem histórica e especificidades regionais. Portanto, é uma região que se caracteriza por um 
relevante grau de exclusão e desigualdade social, e ainda possui democracias em processo de consolidação (PIOVESAN, 2017).

Segundos dados do CONARE, e seguindo a tendência decorrente dos fluxos migratórios gerados por diversos países ao redor do mundo, o maior número de refugiados reconhecidos pelo Estado brasileiro até 2017 foram, respectivamente, de países como Síria (2.771), Congo (953), Colômbia (316), Palestina (295), entre outros (CONARE, 2017).

$\mathrm{O}$ expressivo número de sírios que buscaram refúgio no Estado brasileiro tem como principal motivo a ocorrência de uma série de eventos que acabou sendo conhecida como Primavera Árabe, o que levou o Itamaraty a conceder vistos humanitários, o primeiro país do continente americano a conceder esse tipo de visto para refugiados da Síria (LIMA et al., 2017).

Com relação aos pedidos ao Brasil de refúgio dos venezuelanos, é importante destaca que eles vêm em busca de ter emprestado seus direitos humanos, que para RabinovichBerkman (2013, p. 83) são "[...], direitos humanos que costumam ser chamados de 'segunda geração', apontam mais para aspectos socioeconômicos".

Em 2010, o Brasil recebeu apenas 4 pedidos de refugiados de pessoas da Venezuela. Porém, em 2017, o país recebeu cerca de 17.865 solicitações de refugiados, atingindo um aumento de quase $4.465 \%$ em relação a 2010 (CONARE, 2017).

$\mathrm{Na}$ busca pela recepção do grande fluxo migratório que atravessa as fronteiras, entrando no território brasileiro, há ainda a atuação de comitês instituídos tanto no nível estadual quanto municipal, seguindo estrutura de composição idêntica à adotada pelo CONARE, que conta com a participação de membros das mais diversas instituições, além de entidades governamentais e da ACNUR (LIMA et al., 2017).

A atuação desses comitês é de grande importância para a intermediação entre indivíduos que se encontram em situação de vulnerabilidade e os principais agentes do Estado responsáveis pela defesa dos direitos humanos violados e que culminaram na busca pela proteção institucional.

\section{CONSIDERAÇÕES FINAIS}


A presente pesquisa se propôs a fazer uma análise do panorama geral do refúgio no mundo, discutindo os principais acontecimentos históricos que levaram à adoção de diplomas de proteção legal, bem como à criação de órgãos ou instituições que de alguma forma pudessem oferecer proteção às mesmas pessoas que se encontrem em situação de violação de seus direitos mais básicos pelo Estado de origem ou residência. Nesse sentido, observou-se que, inicialmente, muitos Estados mantiveram-se relutantes em aceitar que um fluxo de pessoas dos mais diversos países do mundo, e que muitas vezes acabam sendo considerados indesejados pudesse entrar em seu território.

A elaboração da Convenção de 1951 e do Protocolo de 1967 podem ser considerados como instrumentos que representaram um divisor de águas na luta pela proteção internacional dos refugiados, uma vez que vários países acabaram ratificando as disposições desses atos jurídicos, passando a incorporá-los em seus ordenamentos jurídicos internos, ou mesmo utilizando como parâmetros para a elaboração de diplomas regionais para a proteção de refugiados, como é o caso, por exemplo, da Declaração de Cartagena de 1984.

Como visto, a própria Lei $\mathrm{n}^{\circ}$ 9.474/1997 publicada no Brasil, adotou tanto as disposições da Convenção de 1951 quanto do Protocolo de 1967, bem como considerou parte das disposições contidas na Declaração de Cartagena de 1984, fazendo com que o Brasil tornasse um país com uma das legislações mais completas e modernas do mundo voltadas à proteção dos refugiados, especialmente na inclusão dos atores que participam das etapas do processo de reconhecimento da condição de refugiado.

Com a promulgação da Constituição Federal de 1988, o Estado brasileiro passou a tratar da questão dos refugiados com maior veemência, tendo como foco principal o respeito aos direitos humanos, previstos em seu art. $4^{\circ}$, II, inclusive concedendo alguns direitos sociais aos refugiados. Porém, o reconhecimento desses direitos não pode ser considerado como medida suficiente para uma efetiva integração dos refugiados à sociedade brasileira que, sobretudo, precisam do reconhecimento de seus direitos políticos, para que, desta forma, tais indivíduos também participem do processo decisório, que os afetará direta e indiretamente.

O estudo realizado com dados catalogados pelo CONARE e pela ACNUR mostrou que em todo o mundo, países como a Síria e o Afeganistão estiveram em uma situação muito delicada, entre 2010 e 2017, em termos de graves violações de direitos humanos que vêm ocorrendo em seus territórios e que, consequentemente, acabou expondo a complexidade no 
tratamento das questões que envolvem a questão do acolhimento de refugiados. Nesse ano de 2021, tem-se se ampliado a saída de pessoas do Afeganistão e o consequente pedido de refúgio em outros países.

Quanto ao panorama do acolhimento de refugiados pelo Estado brasileiro, constatouse que em 2010 o número de reconhecimentos da condição de refugiado apresentou um superávit em relação ao número de pedidos de refugiados, com aproximadamente $304 \%$ dos reconhecimentos em relação ao mesmo, número de formulários. Os anos de 2011 e 2012 mostraram uma queda acentuada no valor dos reconhecimentos, mas ainda em situação positiva, com $25 \%$ e $7 \%$, respetivamente.

Ao analisar os dados referentes ao ano de 2017, observou-se o grande fluxo de venezuelanos que entraram em território brasileiro pela fronteira da Venezuela com o Estado de Roraima. Ressalta-se também que, nos anos de 2018 e no início de 2019, verificou-se a tendência de aumento desse fluxo de venezuelanos. A gravidade da situação pode ser verificada comparando o número de pedidos de refugiados feitos pelos venezuelanos em 2010 (quatro pedidos), com o número de pedidos em 2017 (cerca de dezoito mil).

Por fim, é sabido que o governo brasileiro deve garantir maior agilidade no processamento dos pedidos de refugiados. Além disso, é necessário que o Estado brasileiro direcione maiores investimentos à expansão das estruturas que compõem os órgãos responsáveis pela proteção e acolhimento dos refugiados, de modo que se possa estabelecer políticas públicas voltadas para a promoção dos direitos humanos dos refugiados no Brasil.

\section{REFERÊNCIAS}

ACNUR. Agência da ONU para Refugiados. Protegendo Refugiados no Brasil e no Mundo. Brasília, 2018. Disponível em: http://www.acnur.org/portugues/wpcontent/uploads/2018/02/Protegendo-Refugiados-no-Brasil-e-no-Mundo_ACNUR-2018.pdf. Acesso em agosto de 2021.

ACNUR. Agência da ONU para Refugiados. Manual de procedimentos e critérios para a determinação da condição de refugiado de acordo com a Convenção de 1951 e o Protocolo de 1967 relativos ao Estatuto dos Refugiados. ACNUR, 2011. Disponível em: http://www.acnur.org/fileadmin/scripts/doc.php?file=fileadmin/Documentos/portugues/Public acoes/2013/Manual_de_procedimentos_e_criterios_para_a_determinacao_da_condicao_de_re fugiado. Acesso em agosto de 2021. 
ACNUR. Agência da ONU para Refugiados. Declaração de Cartagena de 1984. Disponível em:

http://www.acnur.org/t3/fileadmin/Documentos/portugues/BD_Legal/Instrumentos_Internaci onais/Declaracao_de_Cartagena.pdf?view=1. Acesso em agosto de 2021.

BARRETO, Luiz Paulo Teles Ferreira. Refúgio no Brasil: a proteção brasileira aos refugiados e seu impacto nas Américas. Brasília: ACNUR, Ministério da Justiça, 2010.

BRASIL. Constituição Federal do Brasil de 1988. Disponível em:

http://www.planalto.gov.br/ccivil_03/constituicao/constituicaocompilado.htm. Acesso em agosto de 2021.

BRASIL. Decreto no $\mathbf{4 2 . 6 2 8}$ de 13 de novembro de 1957. Disponível em: http://www.planalto.gov.br/ccivil_03/decreto/1950-1969/D42628.htm. Acesso em agosto de 2021.

BRASIL. Decreto no 98.602 de 19 de dezembro de 1989. Disponível em: http://www.planalto.gov.br/ccivil_03/decreto/1980-1989/D98602.htm. Acesso em agosto de 2021.

BRASIL. Lei $\mathbf{n}^{\mathbf{0}} \mathbf{1 3 . 4 4 5}$ de 24 de maio de 2017. Disponível em:

http://www.planalto.gov.br/ccivil_03/_ato2015-2018/2017/lei/L13445.htm. Acesso em agosto de 2021.

BRASIL. Lei no $\mathbf{6 . 8 1 5}$ de 19 de agosto de 1980. Disponível em:

http://www.planalto.gov.br/ccivil_03/Leis/L6815.htm. Acesso em agosto de 2021.

BRASIL. Lei no 9.474 de 22 de julho de 1997. Disponível em:

http://www.planalto.gov.br/ccivil_03/leis/L9474.htm. Acesso em agosto de 2021.

CONARE. Comitê Nacional para os Refugiados. Refúgio em Números. $3^{\text {a }}$ ed. Ministério da Justiça, 2017. Disponível em: http://www.justica.gov.br/news/de-10-1-mil-refugiados-apenas5-1-mil-continuam-no-brasil/refugio-emnumeros_1104.pdf/view. Acesso em agosto de 2021.

CONARE. Comitê Nacional para os Refugiados. Regimento Interno. Portaria $\mathrm{n}^{\mathrm{o}} 756 \mathrm{de}$ 05/11/1998. Disponível em: http://www.refworld.org/pdfid/54e742a04.pdf. Acesso em agosto de 2021.

IOM. International Organization for Migration. Glossary on Migration. International Migration Law Series. 2 ed. n. 25, 2011. Disponível em:

http://publications.iom.int/system/files/wmr2015_en.pdf. Acesso em agosto de 2021.

IOM. International Organization for Migration. World Migration Report, 2018. Disponível em: https://publications.iom.int/system/files/pdf/wmr_2018_en.pdf. Acesso em agosto de 2021.

IPEA. Instituto de Pesquisa Econômica Aplicada; ABC. Agência Brasileira de Cooperação - Cooperação brasileira para o desenvolvimento internacional: 2011 - 2013. Brasília: IPEA: 
ABC, 2016. Disponível em:

http://www.ipea.gov.br/portal/images/stories/PDFs/livros/livros/161017_livro_cobradi_2011_ 2013.pdf. Acesso em agosto de 2021.

JUBILUT, Liliana Lyra. O Direito Internacional dos Refugiados. São Paulo: Método, 2017.

JUBILUT, Liliana Lyra. O Direito internacional dos refugiados e sua aplicação no orçamento jurídico brasileiro. São Paulo: Método, 2007. Disponível em:

http://www.acnur.org/fileadmin/scripts/doc.php?file=brasilwp/wpcontent/uploads/2018/02/O-Direito-Internacional-dos-Refugiados-e-sua-

Aplica\%c3\%a7\%c3\%a3o-no-Ordenamento-Jur\%c3\%addico-Brasileiro. Acesso em agosto de 2021.

JUBILUT, Liliana Lyra; GODOY, Gabriel Gualano de (Orgs.), Refúgio no Brasil: Comentários a Lei 9.474/97 - São Paulo: Quartier Latin/ACNUR, 2017. Disponível em: http://www.acnur.org/fileadmin/scripts/doc.php?file=brasilwp/wpcontent/uploads/2018/02/Refúgio-no-Brasil-Comentários-à-lei-9.474-97-2017. Acesso em agosto de 2021.

LIMA, João Brígido Bezerra [et al.]. Refúgio no Brasil: caracterização dos perfis sociodemográficos dos refugiados (1998-2014) - Brasília: Ipea, 2017.

MAZZUOLI, Valério de Oliveira. Curso de direito internacional público. - 9. ed. rev., atual. e ampl. - São Paulo: Editora Revista dos Tribunais, 2015.

MOREIRA, Julia Bertino. Refugiados no Brasil: Reflexões Acerca do Processo de Integração Local, REMHU - Rev. Interdiscip. Mobil. Hum, Brasília, Ano XXII, n. 43, p. 8598, jul./dez. 2014. Disponível em: http://www.scielo.br/pdf/remhu/v22n43/v22n43a06.pdf. Acesso em: 22 ago. 2021. OAS. Convenção Sobre Asilo Territorial. 1954. Disponível em: http://www.oas.org/juridico/portuguese/treaties/a-47.htm. Acesso em agosto de 2021.

OEA. Convenção Americana sobre Direitos Humanos. 1969. Disponível em: http://www.cidh.oas.org/Basicos/Portugues/c.Convencao_Americana.htm. Acesso em agosto de 2021.

ONU. Assembleia Geral. Declaração Universal dos Direitos do Homem. 1948. Disponível em: http://www.onu.org.br/img/2014/09/DUDH.pdf. Acesso em: 24 ago. 2021. ONU, Assembleia Geral. Convenção Sobre o Estatuto dos Apátridas. 1954. Disponível em: http://www.acnur.org/fileadmin/Documentos/portugues/BDL/Convencao_sobre_o_Estatuto_d os_Apatridas_de_1954.pdf. Acesso em agosto de 2021.

ONU. Assembleia Geral. ACNUR. Convenção Relativa ao Estatuto dos Refugiados. 1951. Disponível em:

http://www.acnur.org/t3/fileadmin/Documentos/portugues/BDL/Convencao_relativa_ao_Esta tuto_dos_Refugiados.pdf?view=1. Acesso em agosto de 2021. 
ONU. Assembleia Geral. Protocolo Relativo ao Estatuto dos Refugiados. 1967. Disponível em:

http://www.acnur.org/t3/fileadmin/Documentos/portugues/BDL/Convencao_relativa_ao_Esta tuto_dos_Refugiados.pdf?view=1. Acesso em agosto de 2021.

PIOVESAN, Flávia. Direitos humanos e justiça internacional: um estudo comparativo dos sistemas regionais europeu, interamericano e africano. 7. ed. rev. e atual. São Paulo: Saraiva, 2017.

PIOVESAN, Flávia. Direitos humanos e o direito constitucional internacional. 14. ed., rev. e atual. São Paulo: Saraiva, 2013.

PIOVESAN, Flávia. Temas de direitos humanos. 5. ed. São Paulo: Saraiva, 2012.

PORTELA, Paulo Henrique Gonçalves. Direito Internacional Público e Privado: Incluindo Direitos Humanos e Comunitário. Salvador: JusPodivm, 2017.

PORTELA, Paulo Henrique Gonçalves. Direito Internacional Público e Privado. $-7^{\mathrm{a}}$ ed. rev. amp. atual. - Salvador: Juspodivm, 2015.

RABINOVICH-BERKMAN, Ricardo David. ¿Cómo se hicieron los derechos humanos?: un viaje por la historia de los principales derechos de las personas. Ciudad Autónoma de Buenos Aires: Didot, 2013.

RAMOS, André de Carvalho. Curso de direitos humanos. São Paulo: Saraiva, 2014.

RUSEK, Carlos Roberto. Curso de Direito Internacional Público. 14. ed. São Paulo: LTR, 2017.

SALIBA, Aziz Tuffi. Brasil [Leis etc.]. Legislação de direito internacional. - 10 ed. - São Paulo: Rideel, 2015.

SALLES, Denise Mercedes Nunez Nascimento Lopes; GONÇALVES, Fernanda Cristina Nanci Izidro. A atuação do estado brasileiro na proteção dos refugiados: a distância entre a legislação e a garantia dos direitos humanos, Revista Brasileira de Políticas Públicas e Internacionais, v.1, n.2, Set-Dez/2016. UN. General Assembly. Twenty-first Session, 1966. Disponível em: https://treaties.un.org/doc/source/docs/A_RES_21_2198-E.pdf. Acesso em agosto de 2021 